\title{
Study on the Digital Economy Development Level and Its Influencing Factors in Hubei Province-Based on the Green Development Concept
}

\author{
Chun CHEN ${ }^{\mathrm{a}}$ and Yue SUN $\mathrm{S}^{\mathrm{b}}, 1$ \\ ${ }^{a}$ Hubei Small and Medium Enterprises Research Center, School of Literature, Law and \\ Economics, Wuhan University of Science and Technology, Wuhan, Hubei, China \\ ${ }^{\mathrm{b}}$ School of Literature, Law and Economics, Wuhan University of Science and \\ Technology, Wuhan, Hubei, China
}

\begin{abstract}
Based on the concept of green development, this paper constructs the comprehensive evaluation system to measure the development level of digital economy in Hubei Province and uses the entropy method to calculate the development level with the relevant data during 2013 -2019 years, analyzing the factors affecting the development of the digital economy in Hubei Province. In addition, this paper uses the gray correlation method to explore the relationship between influencing factors. The results show that the popularization level of digital technology and $R \& D$ innovation are the main engines to promote the development of digital economy in Hubei Province. The completed infrastructural facility can positively stimulate the application of digital technology and promote the digital development of enterprises. Therefore, Hubei Province should vigorously promote industrial integration, improve innovation ability, expand application scenarios and optimize digital governance to improve the development level of digital economy, so as to realize the green development of Hubei Province.
\end{abstract}

Keywords. Digital economy, green development, entropy value method, gray correlation method

\section{Introduction and Literature Review}

After the impact of the COVID-19 epidemic, the green economy and the digital economy have become the two major themes of economic stimulus programs in various economies around the world. Green development is a necessary condition for long-term sustainable economic development, and the digital economy is characterized by the high scientific and technological content, low resource consumption and less environmental pollution, which can promote green economic development. On this background, vigorously developing the digital economy is the main starting point for Hubei Province to revive the economy after the epidemic, and also the key for Hubei Province to explore a new path of green development, so as to achieve sustainable

${ }^{1}$ Corresponding Author, Yue SUN, School of Literature, Law and Economics, Wuhan University of Science and Technology, Wuhan, Hubei, China; Email: 1174251998@qq.com. 
economic development. Therefore, how to develop the digital economy better is an important subject for Hubei Province.

The existing research mainly focuses on the relationship between digital economy and green economy, and the development condition of digital economy in Hubei Province. As for the research on the relationship between digital economy and green development, Zhang [1], Carmen [2], Qian et al. [3] found that the green economy and digital economy can promote each other, and should play the synergistic effect to achieve economic recovery. Xue [4], Yee et al. [5], Meleti and Constantinos [6], Howson [7] found that digital technologies such as the Internet of Things and blockchain can promote sustainable economic development, and promote the development of low-carbon economy and green economy, relieve the pressure of the gradual lack of resources, providing new growth points for economic development. When exploring the path of sustainable development in Yunnan Province, Wu [8] put forward suggestions that it should lead the development of digital economy with the concept of green development and accelerate the in-depth integration of informatization and the construction of ecological civilization. Xia et al. [9] believe that the digital economy has been a strong driving force in green production, green consumption, green government affairs and other fields, and has gradually become a new path leading green development, concluding that digital technology can promote the transition of different fields of economic life to sustainable development.

Research on digital economy development in Hubei Province. At present, some domestic scholars have studied the development of digital economy in Hubei Province. $\mathrm{Wu}$ [10] found that the digital economy of Hubei Province has developed rapidly, but there are still four deficiencies in the process of integration with the real economy: the lack of leading enterprises, the communication mechanism is not smooth, the integration into the market barriers, and the high operating costs. Lin and Jiang [11] found that more than half of the listed companies in Hubei A-shares have the basic characteristics of digital enterprises, and the digital economy still has a broad space for development in Hubei Province. Hu and Yang [12] investigated the development status of new employment forms in Hubei Province, and found the positive role of the digital economy in increasing employment, driving innovation, forming a new form of employment, and upgrading the employment structure.

It can be found that the digital economy is booming in Hubei Province, but it still lacks the research on development level and influencing factors of the digital economy in Hubei Province from the perspective of green development concept. The rest of this article is arranged as follows: the second part is the analysis of the digital economic development in Hubei Province, the third part is the construction of the comprehensive evaluation system of the digital economy development level in Hubei Province, the fourth part is the relevant empirical analysis, and the fifth part is the countermeasures and suggestions.

\section{Analysis of the Influencing Factors of the Digital Economy Development in Hubei Province}

There are many factors affecting the development of digital economy, and many scholars have done relevant research. For example, the China Digital Economy Development Report released in March 2018 showed that infrastructure is the key factor and digital talent is the core driving force of digital transformation. Zhang and 
$\mathrm{Wu}$ [13] proposed that the influencing factors include information and communication infrastructure, application of ICT, and development level of ICT. Zhang and Wang [14] also stressed that innovation can improve the network access carrying capacity of information resources. In addition, the development and utilization capacity of information resources can promote the digital basic ecological environment and boost the development of digital economy. Xie and Zhu [15] start from the national system and believe that a more perfect information sharing system and data finance construction are also an important factor in promoting the development of the digital economy.

In the aspect of basic software and hardware, Hubei province still faces the problem of key software jam neck, and the current digital communication infrastructure cannot support the further development of digital economy. The popularization level reflects the popularization level of digital technology in residents' life, but the regional development of Hubei Province is not coordinated, for example, there is a big gap between urban and rural digital penetration rate. The digitization level of enterprises reflects the application level of digital technology in the economic activities of enterprises. However, the e-commerce enterprises in Hubei Province started late, and their contribution rate to the overall local economy is not high. Compared with developed provinces, there is still a big gap. Research and innovation is the key to the development of digital economy. However, the investment in research and innovation in Hubei Province lags far behind that of coastal provinces, and the investment in research and development and the training of research and development personnel need to be further improved.

\section{Construction of Comprehensive Evaluation System of Digital Economy Development Level in Hubei Province}

The comprehensive evaluation system is shown in table 1 .

Table 1. Comprehensive evaluation system.

\begin{tabular}{|c|c|c|c|}
\hline \multirow{10}{*}{$\begin{array}{l}\text { Comprehensive } \\
\text { Evaluation } \\
\text { System of Digital } \\
\text { Economy } \\
\text { Development } \\
\text { Level in Hubei } \\
\text { Province }\end{array}$} & $\begin{array}{l}\text { First level } \\
\text { indicators }\end{array}$ & Second level indicators & Unit \\
\hline & \multirow{2}{*}{$\begin{array}{l}\text { Infrastructure } \\
\text { facilities }\end{array}$} & X1 long-distance optical cable line length & $\begin{array}{l}\text { Thousands of } \\
\text { kilometers }\end{array}$ \\
\hline & & $\mathrm{X} 2$ number of mobile phone base stations & Ten thousand \\
\hline & \multirow[b]{2}{*}{$\begin{array}{l}\text { Popularization } \\
\text { level }\end{array}$} & X3 mobile phone penetration rate & $\%$ \\
\hline & & X4 Internet broadband access users & $\begin{array}{l}\text { Ten thousand } \\
\text { households }\end{array}$ \\
\hline & \multirow{2}{*}{$\begin{array}{l}\text { Enterprise } \\
\text { digitization level }\end{array}$} & X5 E-commerce Sales & $\begin{array}{l}\text { One hundred } \\
\text { million yuan }\end{array}$ \\
\hline & & $\begin{array}{l}\text { X6 number of enterprises with e-commerce } \\
\text { transaction activities }\end{array}$ & One \\
\hline & \multirow{3}{*}{$\mathrm{R} \& \mathrm{D}$ innovation } & $\begin{array}{l}\text { X7 R\&D funds for industrial enterprises above } \\
\text { designated size }\end{array}$ & $\begin{array}{l}\text { One hundred } \\
\text { million yuan }\end{array}$ \\
\hline & & $\begin{array}{l}\text { X8 number of patent applications for high-tech } \\
\text { industries }\end{array}$ & Parts \\
\hline & & $\begin{array}{l}\text { X9 number of large enterprises with R\&D } \\
\text { institutions }\end{array}$ & One \\
\hline
\end{tabular}


In order to evaluate the development level of digital economy in Hubei Province, this paper builds a comprehensive evaluation system to measure the development level of digital economy, and chooses the digital infrastructure, popularization level, enterprise digitization level and R\&D innovation as first level indicators. The infrastructure is measured by the length of long-distance optical cable lines and the number of mobile phone base stations, which reflect the construction of information and communication facilities. The popularity level mainly uses the number of access users of mobile phone and Internet broadband, which reflects the popularity of digital products and equipment in the life of residents in Hubei Province. The digital level of enterprises is described by the e-commerce sales and the number of enterprises with e-commerce transactions, reflecting the use of digital technology in the economic activities of enterprises. Finally, the three secondary indicators of R\&D innovation are R\&D funds, the number of high-tech industry patent application and the number of large enterprises with large enterprises with high-tech industry and large enterprises with $R \& D$ institutions to measure the breadth and depth of research and innovation.

\section{Relevant Empirical Analysis}

\subsection{Entropy Value Method}

The empirical analysis data in this paper came from Hubei Statistical Yearbook, National Bureau of Statistics and Economic and Social Big Data Research Platform from 2013 to 2019.

Based on the theoretical analysis above, it can be found that the indicators are positive, so there is no need to non-negative the data. Calculate the comprehensive index as is in equation (1).

$$
Y_{i, t}=\sum_{j=1}^{n} W_{j} * x_{i j}^{\prime}
$$

Among them, $i=1,2 \ldots 9 ; t=2013,2014, \ldots 2019$.

After a series of calculations, the index weights are shown in table 2.

Table 2. Weight of the evaluation index.

\begin{tabular}{lllllllll}
\hline \multicolumn{2}{l}{ Infrastructure facilities } & \multicolumn{2}{l}{ Popularization level } & \multicolumn{2}{l}{ Enterprise digital level } & \multicolumn{4}{l}{ R \& D \& Innovation } \\
\hline 0.1059 & & 0.3021 & & 0.1757 & \multicolumn{5}{c}{0.4163} & \\
\hline $\mathrm{X} 1$ & $\mathrm{X} 2$ & $\mathrm{X} 3$ & $\mathrm{X} 4$ & $\mathrm{X} 5$ & $\mathrm{X} 6$ & $\mathrm{X} 7$ & $\mathrm{X} 8$ & $\mathrm{X} 9$ \\
0.0843 & 0.0217 & 0.1149 & 0.1872 & 0.0202 & 0.1555 & 0.1634 & 0.0349 & 0.2179 \\
\hline
\end{tabular}

According to the principle of entropy method, finally obtain the development index, shown in table 3 .

The study found that the development index of digital economy in Hubei Province has increased nearly three times during the seven-year period, and the infrastructure, popularization level, enterprise digital level and research and development innovation have generally continued to develop well. Of the four first-level indicators, research, innovation and popularization have the highest entropy, with the sum of 0.7284 . This shows that in the process of digitization, the popularization level and research and 
development innovation are the main driving force for the development of digital economy in Hubei Province. The weight of enterprise digital level is only 0.1757, which shows that the application of digital technology in enterprise production and operation activities is somewhat limited.

Table 3. Comprehensive evaluation index.

\begin{tabular}{llllllll}
\hline Index & $\mathbf{2 0 1 3}$ & $\mathbf{2 0 1 4}$ & $\mathbf{2 0 1 5}$ & $\mathbf{2 0 1 6}$ & $\mathbf{2 0 1 7}$ & $\mathbf{2 0 1 8}$ & $\mathbf{2 0 1 9}$ \\
\hline X1 & 0.24 & 0.26 & 0.26 & 0.27 & 0.27 & 0.27 & 0.26 \\
X2 & 0.19 & 0.28 & 0.38 & 0.42 & 0.46 & 0.5 & 0.66 \\
X3 & 8.76 & 9.1 & 9.13 & 9.15 & 9.72 & 10.81 & 11.04 \\
X4 & 152.22 & 162.77 & 189.86 & 211.85 & 232.62 & 277.13 & 319.73 \\
X5 & 37.22 & 45.96 & 48.2 & 55.36 & 89.09 & 81.82 & 95.61 \\
X6 & 190.98 & 333.74 & 522.7 & 677.9 & 510.72 & 570.13 & 607.92 \\
X7 & 50.96 & 59.32 & 66.57 & 72.89 & 76.65 & 85.89 & 95.86 \\
X8 & 116.94 & 120.57 & 147.69 & 210.96 & 216.82 & 263.1 & 421.99 \\
X9 & 4.58 & 3.27 & 4.36 & 3.92 & 4.79 & 5.67 & 6.97 \\
Comprehensive evaluation value & 562.08 & 735.28 & 989.14 & 1242.71 & 1141.14 & 1295.32 & 1560.04 \\
\hline
\end{tabular}

\subsection{Grey Correlation Method}

Grey correlation method is to measure the correlation between the influencing factors according to the similarity between them and the change of the development trend. This paper calculates the gray relative correlation of the comprehensive evaluation index in the valuation system and use the transformed sequence to calculate the correlation coefficient as the equation (2).

$$
\xi_{i}(k)=\xi\left(X_{o}^{\prime}(k), X_{i}^{\prime}(k)\right)=\frac{\min _{i} \max _{k} \Delta_{i}(k)+\rho \min _{i} \max _{k} \Delta_{i}(k)}{\rho \min _{i} \max _{k}+\Delta_{i}(k)}(i=1,2, \ldots 10)
$$

Get the $\xi_{01}(i)=(1,0.8390,0.6960,0.6363,0.5898,0.6783,0.8548)$

$\xi_{02}(i)=(1,0.6337,0.7208,0.3333,0.5724,0.7484,0.5139)$

$\xi_{03}(i)=(1,0.4658,0.3896,0.4175,0.3370,0.3778,0.5219)$

Then we calculate the results by the equation (3) which is shown below.

$$
\gamma_{0 i}=\frac{1}{N} \sum_{k=1}^{N}(k) \xi_{0,1}
$$

According to the above steps, obtain the gray correlation between the other classification indexes. Specific data is shown in table 4.

Table 4. Gray correlation.

\begin{tabular}{lllll}
\hline $\begin{array}{l}\text { Inter-correlation } \\
\text { degree }\end{array}$ & $\begin{array}{l}\text { Infrastructure } \\
\text { facilities }\end{array}$ & $\begin{array}{l}\text { Popularization } \\
\text { level }\end{array}$ & $\begin{array}{l}\text { Enterprise digital } \\
\text { level }\end{array}$ & $\begin{array}{l}\text { R \& D } \\
\text { Innovation }\end{array}$ \\
\hline Infrastructure facilities & 1 & 0.756 & 0.646 & 0.501 \\
Popularization level & 0.756 & 1 & 0.660 & 0.600 \\
Enterprise digital level & 0.646 & 0.660 & 1 & 0.604 \\
R \& D Innovation & 0.501 & 0.600 & 0.604 & 1 \\
\hline
\end{tabular}


The highest degree of correlation between the infrastructure and the popularization level is the highest, at 0.756 , which shows that the perfect infrastructure is conducive to enterprises to carry out e-commerce business and accelerate the digital development of enterprises. The correlation between research and D innovation and popularization level and enterprise digitization level is about 0.6, with the lowest correlation with infrastructure. This shows that the transformation rate of research and innovation achievements in Hubei Province may not be high, and the scientific and technological achievements have not been well applied to the life of residents and the digitization process of enterprises. The correlation between the popularization level and the digital level of the enterprise is 0.66 , which shows that the more convenient residents to daily use electronic equipment, the greater the probability of online shopping, which is conducive to the development of enterprise e-commerce.

\section{Countermeasures and Suggestions}

\subsection{We Should Expand the Application Scenarios and Strengthen the Application Efforts}

The wider use of digital technology in residents' life, the more conducive to the development of digital economy in Hubei Province. Therefore, we should encourage applying digital technology in all scenarios of residents' lives, intensifying application efforts, striving to solve prominent contradictions and difficult problems in the areas of people's livelihood to achieve green education, green health and green employment to reduce costs and improve efficiency.

\subsection{We Should Promote Industrial Integration and Strengthen Regional Cooperation}

For example, in the field of e-commerce, we need to promote the digital transformation of enterprises, reduce the operating costs of enterprises, improve the overall profitability, and realize green manufacturing, green agriculture and green circulation. In addition, coordinating development between regions can also achieve complementary regional advantages, so as to open up broad prospects for the digital industry and promote green development.

\subsection{We Should Improve Innovation Capacity and Share Resources Reasonably}

We will fully improve our scientific and technological innovation capacity and share digital resources. Promote the coordinated development of enterprises, universities and research institutions, build a professional digital talent team, and explore the possibility of open sharing of data resources to improve resource utilization and use efficiency.

\subsection{We Should Optimize Digital Governance to Bridge the Digital Divide}

In order to solve the problem of digital divide, which indicates the unbalanced development of digital economy between different counties and cities in Hubei Province, one of the effective methods is government information, that is to constantly explore the realization of digital technology in the government office, boost the 
modernization of social governance with digital technology, vigorously promote e-government, promote sustainable development.

\section{Acknowledgments}

This paper was supported by Projects of Hubei Small and Medium Enterprises Research Center (project No.: HBSME2021B03) and Innovation and Entrepreneurship Training Program of Wuhan University of Science and Technology (project No.: 20SB019).

\section{References}

[1] Zhang J 2011 The digital economy and the green economy China Information Industry (05) 75-80.

[2] Carmen N 2011 Integrating digital economy and green economy: Opportunities for sustainable development Theoretical and Empirical Researches in Urban Management 6 (1) 33-43.

[3] Qian L, Fang Q and Lu Z 2020 Collaborative of green economy and digital economy in stimulus Policy Southwest Finance (12) 3-13.

[4] Xue W 2016 Combination of digital economy and green economy: Application of the internet of things Information Construction (03) 103.

[5] Yee M, Lai C, Tee T and Mimi M 2016 The role of higher order thinking skills in green skill development MATEC Web of Conferences 70 1-5.

[6] Vassiliki D, Vasiliki M and Constantinos G 2019 Green economy and smart city Journal of Reliable Intelligent Environments 5 (4) 235-240.

[7] Howson P 2021 Distributed degrowth technology: Challenges for blockchain beyond the green economy Ecological Economics 184 1-7.

[8] Wu T 2018 Research on digital economy development of Yunnan under the concept of green development Smart Age (03) 145-146.

[9] Xia Y, Liu L and Zhou M 2019 Digital economy leads the new path of green development Zhejiang Daily 0410 (010).

[10] Wu L 2019 A brief discussion on promoting the integrated development of digital economy and real economy in Hubei Hubei CPPCC (08) 46-47.

[11] Lin N and Jiang L 2020 Hubei opportunity of digital economy Fulcrum (08) 47-55.

[12] Hu F and Yang J 2021 Research on the impact of digital economy on employment-Based on the development status of new employment form in Hubei Hubei Social Sciences (01) 80-86.

[13] Zhang X and Wu T 2019 Research on spatial differentiation pattern of digital economy development at provincial level in China Research World (10) 34-40.

[14] Zhang Y and Wang J 2020 Has the development of the digital economy reduced the mismatch level of factors in China? Statistics and Information Forum 35 (09) 62-71.

[15] Xie B and Zhu Y 2020 Data finance framework and implementation path exploration Financial Studies (07) 14-23. 